\title{
Possible cobalt-cobalt bridging by a hemiacetal in the dinuclear cobalt complex bearing the ligand bis[3-[2-pyridylmethyleneamino]phenyl] sulfone
}

\author{
Armando M. Guidote, Jr. ${ }^{1,2}$, Tomoko Imajo ${ }^{1}$, Yasuhiko Kurusu ${ }^{1}$, and Yoshiro Masuyama ${ }^{1 *}$ \\ 'Department of Chemistry, Faculty of Science \& Technology \\ Sophia University \\ 7-1 Kioicho, Chiyoda-ku \\ Tokyo 102-8554, JAPAN \\ ${ }^{2}$ Department of Chemistry, School of Science \& Engineering \\ Ateneo de Manila University \\ Loyola Heights, Quezon City \\ Metro Manila 1108, PHILIPPINES
}

\begin{abstract}
A dinuclear cobalt complex bearing the ligand bis(3-(2-pyridylmethyleneamino)phenyl) sulfone (BPMAPS) was prepared. It is proposed that the structure of this is $\left[\mathrm{Co}_{2}(\mathrm{BPMAPS})(\mathrm{m}-\mathrm{OAc})_{2}\left(\right.\right.$ hemi-Et)]PF $\mathrm{P}_{6}$ wherein the cobalt centers are bridged by two carboxylato groups in m-fashion and a hemiacetal with an ethoxy group (hemi-Et). This proposal is based on the similarity of the FT-IR, UV-Vis, and FAB-MS results with the crystallographically characterized dinuclear manganese complex $\left[\mathrm{Mn}_{2}(\mathrm{BPMAPS})(\mathrm{m}-\mathrm{OAc})_{2}(\right.$ hemi-Me $\left.)\right] \mathrm{PF}_{6}$, and elemental analysis results.
\end{abstract}

Keywords: dinuclear; cobalt; complex; synthesis

\section{INTRODUCTION}

Oxidation is very important industrially since millions of tons of intermediate and final products are generated from this process [1, 2]. In general, however, this is energy intensive and produces a considerable amount of dangerous wastes. The use of biomimetic catalysts, modeled from nature's oxidation specialists, metalloenzymes like the oxygen carriers, hemoglobin [3] and hemocyanin [3-6], is one way to address the mentioned concerns. These metalloenzymes activate dioxygen from the air prior to its use for oxidation. One of these is the enzyme hemerythrin (Fig. 1), the dioxygen carrier in certain marine invertebrates such as sipunculids, annelids, priapulids and brachipods $[3,7,8]$.

\footnotetext{
*To whom correspondence should be addressed.
}

A way of modeling metalloenzymes is by mimicking the ligand environment. One of these ligands is bis(3-(2pyridylmethyleneamino)phenyl) sulfone (BPMAPS) which has been previously used in the synthesis of other hemerythrin models: [Mn ${ }_{2}(\mathrm{BPMAPS})(\mu-\mathrm{OAc})_{2}\left(\right.$ hemi-Me)]PF ${ }_{6}$ (1) (Fig. 2), $\left[\mathrm{Mn}_{2}(\mathrm{BPMAPS})(\mu-\mathrm{OAc})_{2}(\mu-1,1-\mathrm{OAc})\left(\eta^{1}-\mathrm{OAc}\right)\right](2)$ (Fig. 3$)$ and

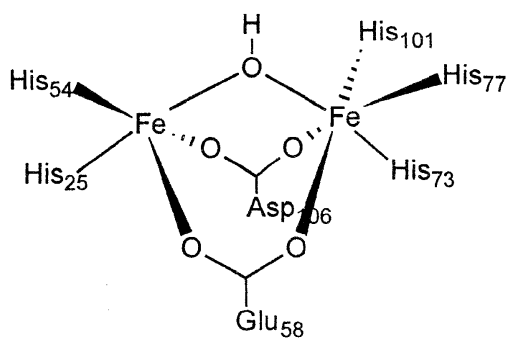

Fig. 1. Core structure of Hemerythrin 


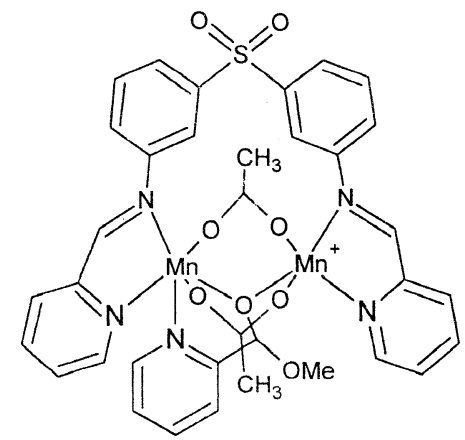

Fig. 2. Structure of Complex 1 (anion not shown).

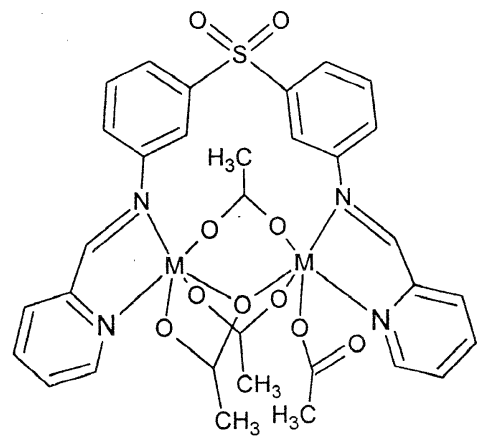

Fig. 3. Structure of Complexes 2-3 ( $M=M n, 2 ; M=C o, 3)$.

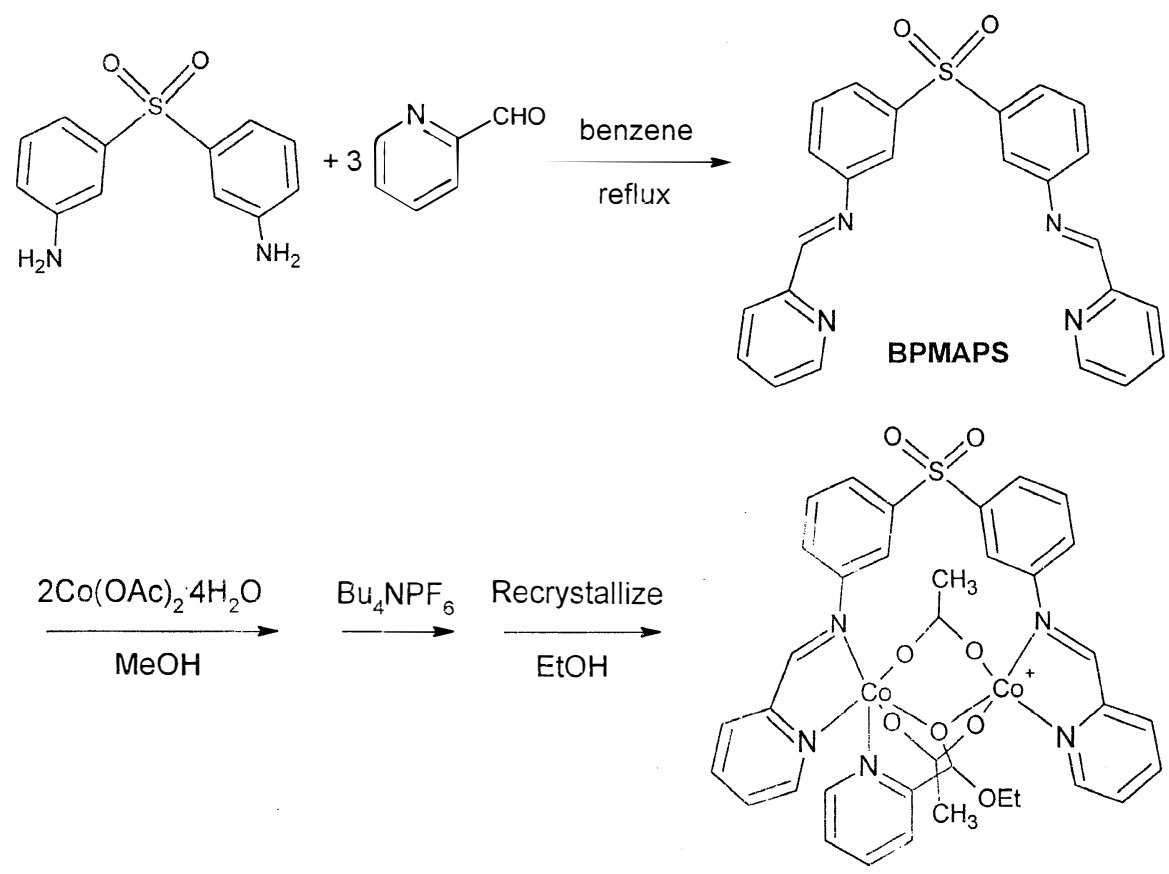

Fig. 4. Synthesis of BPMAPS and Complex 4 (anion not shown).

$\left[\mathrm{Co}_{2}\right.$ (BPMAPS) $\left.(\mu-\mathrm{OAc})_{2}\left\{\mu-\left(\eta^{2}: \eta^{1}\right) \mathrm{OAc}\right\}\left(\eta^{\prime}-\mathrm{OAc}\right)\right]$ (3) (Fig. 3) [9]. All these have been characterized by X-ray analysis. The synthesis (Fig. 4) and characterization of the dicobalt analogue of $1,\left[\mathrm{Co}_{2}(\mathrm{BPMAPS})(\mu-\mathrm{OAc})_{2}(\right.$ hemi-Et) $] \mathrm{PF}_{6}(4)$ is now presented.

\section{EXPERIMENTAL}

Physical methods. Starting materials (reagent grade) and solvents (benzene, reagent grade; DCM, technical grade) for the synthesis of $\mathbf{4}$ were purchased commercially and used as received. Infrared (IR) spectrum of $\mathbf{4}$ was obtained using a Shimadzu FTIR-8300. The UV-Vis spectrum was recorded on a Shimadzu MultiSpec-1500 at room temperature. The mass spectrum was measured on a JEOL JMS-SX102A using Fast Atomic Bombardment (FAB) with $p$-nitrobenzyl alcohol (NBA) as matrix. The mass spectrum was also measured in the Electron Ionization (EI) and Chemical Ionization (CI) modes using a
Finnigan Mat 95STrap high resolution mass spectrometer. For the EI and CI modes, the complex was dissolved in acetonitrile and was introduced using a Direct Insert Probe (DIP). Methane was used as collision gas for the CI-MS analysis. The magnetic susceptibility measurement was done using a CAHN 1000 Electrobalance by way of the Faraday method with $\mathrm{Hg}\left[\mathrm{Co}(\mathrm{SCN})_{4}\right]$ as a reference compound. Elemental analysis was done with the use of a Perkin-Elmer 2400-II.

Preparation and Characterization of BPMAPS [9]. The bis [3(2-pyridylmethyleneamino)phenyl] sulfone ligand (BPMAPS) was prepared by refluxing bis(3-aminophenyl) sulfone ( $0.25 \mathrm{~g}$, $1 \mathrm{mmol})$ and 2-pyridinecarbaldehyde $(0.36 \mathrm{~g}, 3.4 \mathrm{mmol})$ with the catalyst $p$-toluenesulfonic acid $(0.02 \mathrm{~g}, 0.1 \mathrm{mmol})$ in benzene $(30 \mathrm{~mL})$ using a Dean-Stark trap. A nitrogen purge for around 5 $\min$ is done beforehand. Refluxing can be done from anywhere between $10-36 \mathrm{~h}$ with no notable change in yields. After cooling, $\mathrm{CH}_{2} \mathrm{Cl}_{2}(35 \mathrm{~mL})$ was added to the benzene solution. 
This new solution was washed twice with a saturated aqueous solution of $\mathrm{NaHCO}_{3}\left(50 \mathrm{~mL}\right.$ each). The $\mathrm{CH}_{2} \mathrm{Cl}_{2}$ layer was dried over anhydrous $\mathrm{Na}_{2} \mathrm{SO}_{4}$. The solution was concentrated by evaporation after filtration. This was immediately used for the complex syntheses.

Ligand BPMAPS is obtained together with unreacted 2pyridinecarbaldehyde as an oil-like mixture. This prevents the characterization by spectroscopic methods. However, the structure of the complexes 1-3 obtained by X-ray crystallography confirms the structure of ligand BPMAPS.

Preparation of $\left[\mathrm{Co}_{2}(\mathrm{BPMAPS})(\mu-\mathrm{OAc})_{2}(\right.$ hemi-Et $\left.)\right] P F_{6}(4)$. The synthesis of $\mathbf{1}$ and $\mathbf{4}$ are almost the same. At room temperature, the oily mixture which contains the ligand BPMAPS as well as the extra 2-pyridinecarbaldehyde (1:1 ratio) was dis olved in methanol $(5 \mathrm{~mL})$ and were added to a methanol solution $(5 \mathrm{~mL})$ of $\mathrm{Co}(\mathrm{OAc})_{2} \cdot 4 \mathrm{H}_{2} \mathrm{O}(0.54 \mathrm{~g}, 2.2 \mathrm{mmol})$. This was stirred for an hour and afterwards $n-\mathrm{Bu}_{4} \mathrm{NPF}_{6}(0.39 \mathrm{~g}, 1 \mathrm{mmol})$ was added. The solution was stirred overnight and the complex was obtained as a brown powder. This powder was added to ethanol and the mixture was brought to reflux temperature. Ethanol is added in increments until the solution is clear. The red-brown crystals ( $0.44 \mathrm{~g}, 45 \%)$ were obtained by overnight diffusion of diethyl ether to the filtered ethanol solution of 4 .

\section{RESULTS AND DISCUSSION}

The synthesis of $\mathbf{4}$ was the same as $\mathbf{1}$ and the two show very similar results after spectroscopic analysis. The two are stable up to $250^{\circ} \mathrm{C}$. These are expected of salts and quite unlike 2-3, which decomposed at $165^{\circ} \mathrm{C}$ and $200^{\circ} \mathrm{C}$, respectively.

The FT-IR spectra $\left(400-1800 \mathrm{~cm}^{-1}\right)$ of 1 and 4 are shown in Fig. 5. Assignments for major stretchings are shown in Table 1 . The spectra of $\mathbf{1}$ and $\mathbf{4}$ are almost the same. The spectra of $\mathbf{2}$ and $\mathbf{3}$ (not shown) are almost alike but still similar with $\mathbf{1}$ and $\mathbf{4}$. The two sets of spectra differ mainly with the absence of the $v\left(\mathrm{PF}_{6}\right)$ signal for $\mathbf{2}$ and $\mathbf{3}$.

The UV-visible spectra of 1 and $\mathbf{4}$ (Fig. 6) were taken at room temperature using methanol as solvent and the two are similar. On the other hand, the electronic spectra of 2-3 (not shown) are similar to each other but different from 1 and 4 . The assignments are given in Table 2.

The results of the Fast Atom Bombardment mass spectral analyses of complexes 1-4 are summarized in Table 3. It can be clearly seen that results for $\mathbf{1}$ and $\mathbf{4}$ are quite similar. ElectronImpact and Chemical Ionization nass spectral analyses were also done for 4 but the results show fragmentation patterns that are difficult to rationalize.

The magnetic moment of 4 was $4.82 \mathrm{BM}$ and this result is near the typical values for cobalt in the high spin +2 oxidation state [10].

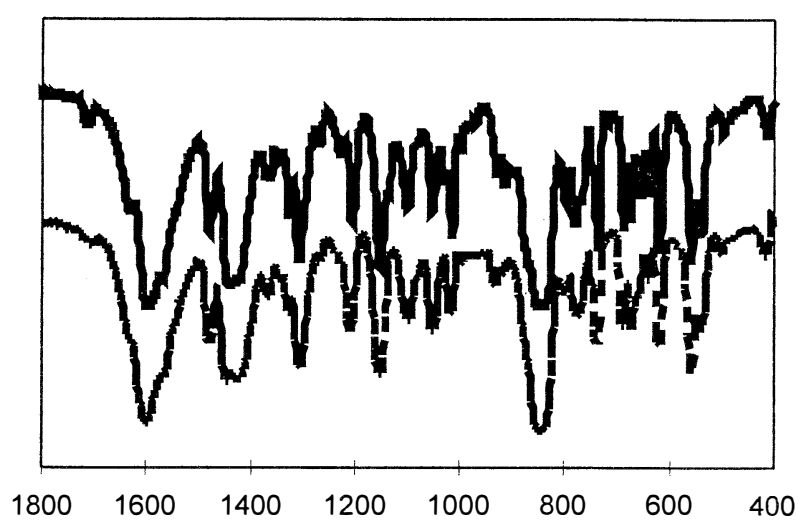

Fig. 5. FT-IR spectra $\left(\mathrm{cm}^{-1}\right)$ of 1 (top) and 4 (bottom).

Table 1. FT-IR assignments for $1-4\left(\mathrm{~cm}^{-1}\right)$.

\begin{tabular}{c|c|c|c|c}
\hline \hline $\boldsymbol{l}$ & 2 & 3 & $\mathbf{4}$ & Assignment \\
\hline \hline 1595 & 1560 & 1560 & 1599 & $v(\mathrm{O}-\mathrm{C}-\mathrm{O})$ \\
1479 & 1477 & 1477 & 1477 & $v(\mathrm{C}=\mathrm{C}$ aromatic $)$ \\
1443 & 1418 & 1412 & 1425 & $v(\mathrm{C}=\mathrm{C}$ aromatic $)$ \\
1308 & 1306 & 1304 & 1306 & $v_{\text {as }}\left(\mathrm{SO}_{2}\right)$ \\
1151 & 1150 & 1151 & 1151 & $v_{\mathrm{s}}\left(\mathrm{SO}_{2}\right)$ \\
845 & & & 845 & $v\left(\mathrm{PF}_{6}\right)$ \\
\hline
\end{tabular}

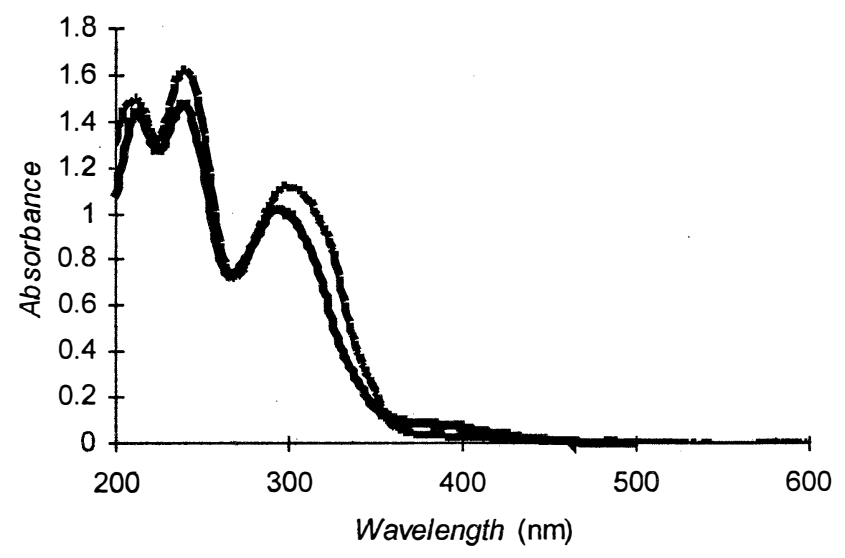

Fig. 6. Electronic spectra of $1\left(4.4 \times 10^{-5} \mathrm{M}\right)$ and $4\left(4.5 \times 10^{-5} \mathrm{M}\right)$ in methanol $(\mathbf{1}=$ solid line, $4=$ broken line $)$.

Table 2. UV-visible spectroscopic results for 1-4 (nm).

\begin{tabular}{c|c|c|c}
\hline \hline $\begin{array}{c}1 \\
\left(\varepsilon / \mathrm{M}^{-1} \mathrm{~cm}^{-1}\right)\end{array}$ & $\begin{array}{c}2 \\
\left(\varepsilon / \mathrm{M}^{-1} \mathrm{~cm}^{-1}\right)\end{array}$ & $\begin{array}{c}3 \\
\left(\varepsilon / \mathrm{M}^{-1} \mathrm{~cm}^{-1}\right)\end{array}$ & $\begin{array}{c}4 \\
\left(\varepsilon / \mathrm{M}^{-1} \mathrm{~cm}^{-1}\right)\end{array}$ \\
\hline \hline $210(34000)$ & - & - & $212(32000)$ \\
$240(37000)$ & $234(39000)$ & $236(33000)$ & $239(33000)$ \\
$298^{*}(25000)$ & $313 *(8300)$ & $309 *(12000)$ & $294 *(23000)$ \\
\hline
\end{tabular}

*LMCT: Ligand-to-Metal Charge Transfer 
Table 3. FAB-MS assignments for $1-4$

$(1-2, M=M n ; 3-4, M=C o)$.

\begin{tabular}{c|c|c|c|c}
\hline \hline $\boldsymbol{1}$ & $\mathbf{2}$ & $\mathbf{3}$ & $\mathbf{4}$ & Assignment \\
\hline \hline 481 & 481 & 485 & 485 & MBPMAPS \\
654 & 654 & 662 & 662 & $\mathrm{M}_{2}\left(\right.$ BPMAPS) $(\mathrm{OAc})_{2}$ \\
- & $713^{*}$ & 721 & - & $\mathrm{M}_{2}(\mathrm{BPMAPS})(\mathrm{OAc})_{3}$ \\
806 & 806 & $814^{*}$ & $814^{*}$ & $\mathrm{M}_{2}$ (BPMAPS) $(\mathrm{OAc})_{2}$ \\
\hline
\end{tabular}

${ }^{*}$ Base peak, (NBA = nitrobenzyl alcohol, the matrix)

Table 4. Elemental analyses results for 1 and 4.

\begin{tabular}{c|c|c|c|c}
\hline \hline ormula Calculated for: & & $C \%$ & $H \%$ & \multirow{2}{*}{$N \%$} \\
\hline \hline $\mathrm{C}_{35} \mathrm{H}_{32} \mathrm{~N}_{5} \mathrm{O}_{8} \mathrm{SMn}_{2} \mathrm{PF}_{6}$ & 1, Calculated & 44.84 & 3.44 & 7.47 \\
$(\mathrm{MW}=937.57 \mathrm{~g} / \mathrm{mol})$ & 1, Found & 44.58 & 3.34 & 7.71 \\
\hline $\mathrm{C}_{36} \mathrm{H}_{34} \mathrm{~N}_{5} \mathrm{O}_{8} \mathrm{SCo}_{2} \mathrm{PF}_{6}$ & 4, Calculated & 45.06 & 3.57 & 7.30 \\
$(\mathrm{MW}=959.59 \mathrm{~g} / \mathrm{mol})$ & 4, Found & 43.39 & 3.41 & 7.00 \\
\hline
\end{tabular}

The FAB-MS results specifically support the presence of the two carboxylato groups and the ligand BPMAPS. Comparison of the IR, UV-vis and FAB-MS of complexes 1 and $\mathbf{4}$ indicate very strong similarity between the two and the presence of the hemiacetal can be deduced from these similarities. With the hemiacetal, there are two possibilities, either with a methoxy or an ethoxy group. The structure with an ethoxy group better conforms to the elemental analysis result (Table 4). This is chemically possible since the recrystallization was done with ethanol. Initially it was hemi-Me but the methoxy group was replaced by the more abundant ethanol. It is therefore, proposed that the structure of the dinuclear cobalt complex 4 is $\left[\mathrm{Co}_{2}(\mathrm{BPMAPS})(\mu-\mathrm{OAc})_{2}(\right.$ hemi-Et) $] \mathrm{PF}_{6}$ with the ligand BPMAPS bound to the cobalt centers through the imine and pyridine nitrogen atoms. The cobalt centers are bridged by two carboxylato groups in $\mu$-fashion, as well as a hemiacetal with an ethoxy group. With this, a dinuclear cobalt centered hemerythrin model was successfully prepared.

\section{ACKNOWLEDGMENT}

AMG would like to thank the Japanese Government Ministry of Education, Science, Sports and Culture (Monbusho) for his scholarship. We are grateful for partial funding from the University Research Council (URC) of the Ateneo de Manila University and to Ms. Estrella Gonzales and Mr. Giovanni Lao of the (Philippine) National Chemistry Instrumentation Center for the EI-MS and CI-MS measurements. We would also like to thank Dr Y. Inomata of Sophia University for her help with the magnetic measurements.

\section{REFERENCES}

1. Parshall, G. W. and Ittel, S. D. Homogeneous Catalysis, $2^{\text {nd }}$ Ed., p. 137. (John Wiley \& Sons: New York, 1992).

2. Storck, W. J. $C \& E N .77,13$ (1999).

3. Fenton, D. E. Biocoordination Chemistry, p. 21. (Oxford University Press, 1995).

4. Kitajima, N., Moro-oka, Y. J. Chem. Soc., Dalton Trans. 2655 (1993).

5. Kitajima, N., Moro-oka, Y. Chem. Rev. 94, 737 (1994).

6. Guidote, A. Jr. M., Ando, K., Terada, K., Kurusu, Y., Nagao, H., and Masuyama, Y. Inorg. Chim. Acta. 324, 203(2001).

7. Wilkins, P. C. and Wilkins, R. G. Coord. Chem. Rev. 79, 195(1987).

8. Feig, A. L. and Lippard, S. J. Chem. Rev. 94, 759 (1994).

9. Guidote, A. Jr. M., Ando, K., Kurusu, Y., Nagao, H., and Masuyama, Y. Inorg. Chim. Acta 314, 27 (2001).

10. Cotton, F. A., Wilkinson, G., Murillo, C. A., and Bochmann, M. Advanced Inorganic Chemistry, $6^{\text {th }}$ Ed., p. 820. (John Wiley \& Sons: New York, 1999). 